\title{
Overexpression of miRNA-221 promotes cell proliferation by targeting the apoptotic protease activating factor-1 and indicates a poor prognosis in ovarian cancer
}

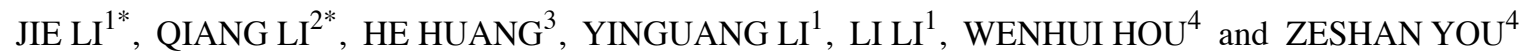 \\ ${ }^{1}$ Department of Gynecology, The Eastern Hospital of the First Affiliated Hospital of Sun Yat-sen University, \\ Guangzhou, Guangdong 510700; ${ }^{2}$ Department of Obstetrics and Gynecology, Tongji Hospital, Tongji Medical College, \\ Huazhong University of Science and Technology, Wuhan, Hubei 430030; ${ }^{3}$ Department of Gynecology, \\ Sun Yat-sen University Cancer Center, Guangzhou, Guangdong 510000; ${ }^{4}$ Department of Gynecology, \\ The First Affiliated Hospital of Sun Yat-sen University, Guangzhou, Guangdong 510080, P.R. China
}

Received December 21, 2016; Accepted February 16, 2017

DOI: $10.3892 /$ ijo. 2017.3898

\begin{abstract}
MicroRNAs are a class of small non-coding, endogenous RNAs involved in cancer development and progression. MicroRNA-221 (mir-221) has been reported to have both an oncogenic and tumor-suppressive role in human tumors, but the role of miR-221 in ovarian cancer is poorly understood. In the present study, the expression levels of miR-221 and the apoptosis protease activating factor 1 (APAF1) protein in 63 samples of ovarian cancer tissues and the cell lines, IOSE25, A2780, OVCAR3, SKOV3 and 3AO were detected by quantitative reverse-transcription polymerase chain reaction (qRT-PCR) and western blot analysis, respectively. Cell proliferation was measured using Cell Counting kit-8 (CCK-8); cell migration and invasion were detected using a Transwell assay; cell apoptosis was evaluated by flow cytometry and Hoechst staining, and a luciferase assay was performed to verify a putative target site of miR-221 in the 3'-UTR of APAFl mRNA. Expression of miR-221 was upregulated in ovarian cancer tissues. Patients with increased miR-221 expression levels had a reduced disease-free survival $(\mathrm{P}=0.0014)$ and overall survival $(\mathrm{P}=0.0058)$ compared with those with low miR-221 expression. Transfection of SKOV3 and A2780 cell lines with miR-221 inhibitor induced APAF1 protein expression, suppressed cell proliferation and migration and promoted
\end{abstract}

Correspondence to: Professor Zeshan You, Department of Gynecology, The First Affiliated Hospital of Sun Yat-sen University, No. 58, Zhongshan Road II, Guangzhou, Guangdong 510080, P.R. China

E-mail: youzeshan888@21cn.com; zeshanyoudoctor@yeah.net

*Contributed equally

Key words: ovarian cancer, miRNA-221, prognosis, apoptosis protease activating factor 1 , cell proliferation, apoptosis tumor cell apoptosis. In conclusion, the $A P A F 1$ gene was confirmed as a direct target of miR-221 and overexpression of APAF1 suppressed ovarian cancer cell proliferation and induced cell apoptosis in vitro. These findings indicate that miR-221-APAF1 should be studied further as a potential new diagnostic or prognostic biomarker for ovarian cancer.

\section{Introduction}

Ovarian cancer is a malignancy that is associated with a high mortality. Worldwide, this form of cancer represents $\sim 3 \%$ of all cancers in women and is the fifth leading cause of death in the female population (1). Despite developments in cancer therapy in the past two decades, the mortality from ovarian cancer has remained constant (1). Early diagnosis and improved prognostic markers are required to improve patient survival rates for ovarian cancer (2). The identification of new molecular markers may also lead to more effective and targeted therapies for ovarian cancer.

MicroRNAs (miRNAs) are a class of small, non-coding, endogenous RNAs that are 22 nucleotides in length and play important roles in post-transcriptional regulation (3). miRNAs can inhibit target gene expression by binding to the 3'-untranslated region (3'-UTR) of target mRNA, which results in either mRNA degradation or prevention of translation to protein expression $(4,5)$. miRNAs have several roles in normal cellular processes involving cell proliferation, apoptosis, cell differentiation and stress response (6-8). In recent years, miRNAs have received attention in cancer research, as 98 miRNAs are located at genomic regions involved in malignancy, indicating that miRNAs could be used as diagnostic and prognostic biomarkers (9). However, miRNAs have been reported to have both tumor suppressor and oncogenic activities (10).

In particular, miR-221 has been reported to have both tumor suppressor and oncogenic roles in different types of human cancer, including breast cancer $(11,12)$ and hepatocellular carcinoma (13). Recently, miR-221 has been shown to have as tumor suppressor role in non-small cell lung cancer (14). miRNA-221 is encoded by a gene located on chromosome 
Xp11.3 and acts as an oncogene in tumors of epithelial origin and as an oncosuppressor in hemopoietic malignancies (12-14). The increasing awareness of the role of miRNAs in human malignancy has raised the possibility of their future role as diagnostic and prognostic biomarkers $(15,16)$. Recent studies have also indicated that miRNAs may be potential therapeutic targets in human malignancy $(17,18)$.

In 2007, a study in human prostate cancer cell lines demonstrated that miR-221 mediated its effects on the control of cell proliferation by targeting $\mathrm{p} 27^{\mathrm{Kip} 1}(20)$. It is now known that miR-221 exerts its oncogenic effects through the inhibition of the cyclin-dependent kinase (CDK) inhibitors $\mathrm{p} 27^{\mathrm{Kipl}}$ and $\mathrm{p} 57$, upregulating ZEB2, an epithelial-to-mesenchymal transition (EMT)-inducing gene through TRPS1 $(19,20)$. Overexpression of miR-221 in malignant glioblastoma cells has been shown to promote the cell cycle through G1 into $S$ phase and to promote cell apoptosis (21). In addition, miR-221 has been shown to be downregulated in Kaposi's sarcoma-associated herpes virusassociated cancers, including Kaposi sarcoma and primary effusion lymphoma (PELs) (22). A recent study has shown that the overexpression of miR-221 enhances chemosensitivity to gemcitabine in cholangiocarcinoma cells (23). These data demonstrate that miR-221 has a bimodal function in the tumorigenesis of human cancers.

Apoptotic protease activating factor 1 (APAF1) is a crucial component of the apoptosome that is present in humans and mice $(24,25)$ and is assembled in response to cellular stress, including DNA damage, hypoxia and oncogene activation (26-28). APAF1 is closely related to several oncogenes and tumor suppressor genes, including B-cell lymphoma-2 (Bcl-2) and p53 (29,30). A series of studies have shown that APAF1 protein is an important apoptosis factor that is abnormally expressed in cancer tissues (27,31). APAF1 is downregulated in human colorectal cancer, and its expression is associated with adverse patient prognosis $(32,33)$.

Since the role of miR-221 in the development and progression of ovarian cancer remains unknown, the present study was done using both established tumor cell lines and tumor tissue samples from patients with histopathologically confirmed primary ovarian carcinoma.

\section{Materials and methods}

Patients studied and tissue collection. Sixty-three patients with histopathologically diagnosed ovarian cancer had tumor tissue sampled as part of their routine diagnosis with adjacent normal tissue samples. All patients underwent surgery at the First Affiliated Hospital of Sun Yat-sen University between 2008 and 2010. The diagnosis of primary ovarian cancer was based on histopathological evaluation according to the International Federation of Obstetrics and Gynecology (FIGO) criteria. Clinical pathology information was available for all patient samples, as shown in Table I. No other treatments were conducted in these patients before surgery and tissue sampling. Informed patient consents were obtained from every study participant. The present study was approved by the Research Ethics Committee of the First Affiliated Hospital of Sun Yat-sen University. All tissues were collected and immediately frozen in liquid nitrogen and stored at $-80^{\circ} \mathrm{C}$ for further study.
Table I. Clinicopathological characteristics and GAS5 expression in 63 patient samples of ovarian cancer.

\begin{tabular}{|c|c|}
\hline Clinical parameters & No. of cases $(\%)$ \\
\hline \multicolumn{2}{|l|}{ Age (years) } \\
\hline$<55$ & $29(46.03)$ \\
\hline$>55$ & $34(53.96)$ \\
\hline \multicolumn{2}{|l|}{ Size $(\mathrm{cm})$} \\
\hline$>5$ & $33(52.38)$ \\
\hline$<5$ & $30(47.62)$ \\
\hline \multicolumn{2}{|c|}{ Histologic differentiation } \\
\hline Well & $5(7.94)$ \\
\hline Moderate & $23(36.51)$ \\
\hline Poor & $28(44.44)$ \\
\hline Undifferentiated & $7(11.11)$ \\
\hline \multicolumn{2}{|l|}{ Invasion depth } \\
\hline $\mathrm{T} 1$ & $15(23.81)$ \\
\hline $\mathrm{T} 2$ & $16(25.40)$ \\
\hline $\mathrm{T} 3$ & $18(28.57)$ \\
\hline $\mathrm{T} 4$ & $14(22.22)$ \\
\hline \multicolumn{2}{|l|}{ FIGO stages } \\
\hline I & $8(12.70)$ \\
\hline II & $22(34.92)$ \\
\hline III & $27(42.86)$ \\
\hline IV & $6(9.52)$ \\
\hline \multicolumn{2}{|l|}{ Lymphatic metastasis } \\
\hline Yes & $30(47.62)$ \\
\hline No & $33(52.38)$ \\
\hline \multicolumn{2}{|l|}{ Distant metastasis } \\
\hline Yes & $8(12.70)$ \\
\hline No & $55(87.30)$ \\
\hline \multicolumn{2}{|c|}{ Expression of miR-221 } \\
\hline Low expression & $31(50.79)$ \\
\hline High expression & $32(49.21)$ \\
\hline
\end{tabular}

Cell culture. Human ovarian surface epithelial cells (IOSE25) were immortalized and cultured as previously described (34). Four human ovarian cancer cell lines, A2780, OVCAR3, SKOV3 and $3 \mathrm{AO}$ were purchased from the Cell Bank of the Chinese Academy of Sciences (Shanghai, China) and the American Type Culture Collection (ATCC; Manassas, VA, USA), respectively.

The ovarian cancer cell lines were maintained according to the vendor's instructions. Briefly, A2780 and 3AO cell lines were routinely cultured in Dulbecco's modified Eagle's medium (DMEM) with $10 \%$ fetal bovine serum (FBS; Gibco, Carlsbad, CA, USA). SKOV3 cells were cultured in McCoy's 5A Modified Medium (ATCC) with 10\% FBS (Gibco). OVCAR3 cells were cultured in RPMI-1640 medium (ATCC) with 20\% FBS (Gibco). All the media contained 1\% penicillin-streptomycin $(100 \mathrm{U} / \mathrm{ml}$ penicillin and $100 \mu \mathrm{g} / \mathrm{ml}$ streptomycin). The ovarian cancer cells were cultured and maintained in a humidified incubator at $37^{\circ} \mathrm{C}$ and supplemented with $5 \% \mathrm{CO}_{2}$. 
Plasmid construction. The apoptotic protease activating factor 1 (APAF1) 3'-untranslated region (3'-UTR) containing putative binding sites for microRNA-221 (miR-221) was cloned downstream of the psi-CHECK2 vector (Promega, Madison, WI, USA) and named as APAF1-3'UTR-WT. APAF1 mutant 3'-UTR recombinant plasmid was generated by QuikChange Site-Directed Mutagenesis kit (Stratagene, La Jolla, CA, USA), which generated a mutation of $7 \mathrm{bp}$ from AUGUAGC to UACGCGU in the predicted miR-221 target binding site, named as APAF1-3'UTR-MUT. The full-length cDNA encoding human APAF1 was amplified and the recombinant plasmid, pcDNA3.1-APAF1 was constructed. All plasmids were confirmed by DNA sequencing.

Cell transfection. The miR-221 mimics, miR-221 inhibitor and scrambled sequence pre-miR negative control (NC) were purchased from a commercial manufacturer (Guangzhou RiboBio, Co., Ltd., Guangzhou, China). Ovarian cancer cells $(100 \mu \mathrm{l})$ were seeded in 24 -well plates $\left(1 \times 10^{6}\right.$ cells $\left./ \mathrm{ml}\right)$ and incubated for $24 \mathrm{~h}$, then cells were transfected with miRNA mimics/inhibitor $(50 \mathrm{mM})$ or vectors $(2 \mu \mathrm{g})$ using Lipofectamine 2000 (Invitrogen, Carlsbad, CA, USA) in serum-free medium in accordance with the manufacturer's instructions.

RNA extraction and quantitative real-time PCR (qRT-PCR) analysis. TRIzol reagent (Invitrogen) was used to extract total RNA from tissue samples or cultured cells. For quantitative real-time polymerase chain reaction (qRT-PCR), $2 \mu \mathrm{g}$ of total RNA was used for the reverse transcription reaction and cDNA synthesis by using a Reverse Transcription kit (Takara, Dalian, China). Quantitative real-time PCR analysis was performed with SYBR-Green Real-Time Master Mix (Toyobo, Co., Ltd, Osaka, Japan). Results were normalized to a constitutive expression gene, GAPHD. The relative expression of miRNA-221 was detected using a SYBR PrimeScript miRNA RT PCR kit (Takara) in accordance with the manufacturer's instructions and U6 was used as an internal control. The gene-specific primers were synthesized by Sangon Biotech, Co., Ltd. (Shanghai, China) (Table III). qRT-PCR and data collection were performed on an Applied Biosystems 7500 Sequence Detection system (Applied Biosystems, Foster City, CA, USA). The relative expression of miR-221 and APAF1 were calculated and normalized using the $2^{-\Delta \Delta \mathrm{Ct}}$ method.

Protein extraction and western blot analysis. Total proteins were extracted from tissue samples or cultured cells with SDS lysis buffer (Beyotime Institute of Biotechnology, Haimen, China) on ice for $20 \mathrm{~min}$ and the protein concentrations were determined using BCA protein assay kit (Pierce, Rockford, IL, USA). Equal amounts of total proteins were separated by $10 \%$ SDS-polyacrylamide gel electrophoresis (SDS-PAGE) at $120 \mathrm{~V}$ for $2 \mathrm{~h}$, transferred to $0.22 \mu \mathrm{m}$ polyvinylidene difluoride membranes (PVDF) (Millipore, Billerica, MA, USA) and incubated with APAF1 antibodies (1:1,000, ab32372; Abcam). Proteins were detected by enhanced chemiluminescence (ECL) as described by the manufacturer (Beyotime Institute of Biotechnology) and the intensity of the bands was quantified by densitometry (Quantity One software; Bio-Rad Laboratories, Hercules, CA, USA). Results were normalized to a constitutive expression gene, GAPHD (1:2,000, ab9485; Abcam).
Luciferase assays. For the reporter assay, $1 \times 10^{5}$ cells were cultured in 24-well plates one day before transfection. A total of $100 \mathrm{ng}$ APAF1-3'UTR-WT or -MUT vectors were co-transfected with $50 \mathrm{nM}$ miR-221 mimics or negative control into cells using Lipofectamine 2000 reagent. After $48 \mathrm{~h}$ of transfection, luciferase activities were measured using Dual-luciferase reporter assay system (Promega) according to the manufacturer's instructions. Firefly luciferase activity was normalized to Renilla luciferase activity.

Cell proliferation assays. Cell Counting kit-8 (CCK-8; Dojindo Laboratories, Kumamoto, Japan) was used to examine the cell proliferation, according to the manufacturer's instruction. Briefly, $2 \times 10^{4}$ cells were seeded into a 96-well plate. Cell viability was evaluated with CCK-8 at daily intervals from the next 24,48 and $72 \mathrm{~h}$ after seeding. Following the CCK- 8 assay at $37^{\circ} \mathrm{C}$ for $1 \mathrm{~h}$, ovarian cancer cells were used to measure the absorbency at $450 \mathrm{~nm}$ using a microplate reader Thermo Plate (Rayto Life and Analytical Science, Co., Ltd., Hamburg, Germany).

Cell migration and invasion assays. A Transwell migration assay and a Matrigel invasion assay were performed separately using 24-well Transwell inserts with $8-\mu \mathrm{m}$ pore size (Corning Costar Corp., Corning, NY, USA). For the Transwell migration assay, $2 \times 10^{4}$ ovarian cancer cells were plated in $100 \mu \mathrm{l}$ corresponding culture medium without FBS into the upper chamber of a Transwell insert with a non-coated membrane. For the Matrigel invasion assay, $4 \times 10^{4}$ ovarian cancer cells were suspended in $100 \mu \mathrm{l}$ serum-free corresponding culture medium were loaded in the upper Matrigel-coated chamber. In both assays, $500 \mu \mathrm{l}$ of culture medium containing $20 \% \mathrm{FBS}$ was added to the lower chamber. Cells were then allowed to migrate or invade for $24 \mathrm{~h}$ at $37^{\circ} \mathrm{C}$. The cells that migrated or invaded into the bottom chamber were fixed with $100 \%$ methanol for $30 \mathrm{~min}$ and stained using $0.5 \%$ crystal violet (Sigma-Aldrich, St. Louis, MO, USA) for $20 \mathrm{~min}$, and the permeating cells were counted under a phase-contrast microscope (Olympus Corp., Tokyo, Japan).

Cell apoptosis. Cell apoptosis was studied using an Annexin V-fluorescein isothiocyanate (FITC) and propidium iodide (PI) apoptosis detection kit (BestBio, Shanghai China) with flow cytometry and in accordance with the manufacturer's instruction. Briefly, $1 \times 10^{6}$ cells were harvested and resuspended in cold PBS, and then stained using the Annexin V FITC/PI apoptosis detection kit according to the manufacturer's instructions. Samples were analyzed using Becton-Dickinson flow cytometer. Annexin V(+)/PI(-) and Annexin $\mathrm{V}(+) / \mathrm{PI}(+)$ represented the ovarian cancer cells in early and late apoptosis or necrosis, respectively.

Hoechst 33342 nuclear staining method was performed to detect cell apoptosis. Briefly, cells were cultured with Hoechst 33342 blue fluorescent nuclear dye (Sigma-Aldrich) in 6-well cell culture plates for $30 \mathrm{~min}$. The nuclear morphology was examined using fluorescence microscopy with a filter for Hoechst 33342 at $365 \mathrm{~nm}$.

Statistical analysis. All results were expressed as the mean \pm standard deviation (SD). Statistical analysis was 
Table II. The relationship between the GAS5 expression and the clinicopathological factors in ovarian cancer patients.

\begin{tabular}{|c|c|c|c|}
\hline \multirow[b]{2}{*}{ Clinical parameter } & \multicolumn{2}{|c|}{ miR-221 } & \multirow{2}{*}{$\begin{array}{l}\text { hi-squared test } \\
\text { P-value }\end{array}$} \\
\hline & Group 1 & Group 2 & \\
\hline Age (years) & & & 0.8052 \\
\hline$<55$ & 14 & 15 & \\
\hline$>55$ & 18 & 16 & \\
\hline Size $(\mathrm{cm})$ & & & 0.0010 \\
\hline$>5$ & 9 & 24 & \\
\hline$<5$ & 21 & 9 & \\
\hline Histologic differentiation & & & 0.9463 \\
\hline Well & 3 & 2 & \\
\hline Moderate & 11 & 12 & \\
\hline Poor & 14 & 14 & \\
\hline Undifferentiated & 4 & 3 & \\
\hline Invasion depth & & & 0.0003 \\
\hline $\mathrm{T} 1$ & 10 & 5 & \\
\hline $\mathrm{T} 2$ & 13 & 3 & \\
\hline $\mathrm{T} 3$ & 4 & 14 & \\
\hline $\mathrm{T} 4$ & 3 & 12 & \\
\hline FIGO stages & & & 0.0076 \\
\hline I & 6 & 2 & \\
\hline II & 15 & 7 & \\
\hline III & 8 & 19 & \\
\hline IV & 1 & 5 & \\
\hline Lymphatic metastasis & & & 0.4985 \\
\hline Yes & 18 & 12 & \\
\hline No & 17 & 16 & \\
\hline Distant metastasis & & & 0.6723 \\
\hline Yes & 3 & 5 & \\
\hline No & 25 & 30 & \\
\hline
\end{tabular}

performed using the SPSS 18.0 (SPSS, Inc., Chicago, IL, USA). Statistical significance between the groups was determined using the Student's t-test or the Chi-square test. Survival analysis was performed using the Kaplan-Meier method. The log-rank (Mantel-Cox) test was used to compare the differences between the patient groups.

\section{Results}

miR-221 upregulation in human ovarian cancer tissues. Fig. 1A shows that miR-221 was upregulated in ovarian cancer tissues compared with matched adjacent normal tissues in 63 cases, using quantitative reverse transcription polymerase chain reaction (qRT-PCR). In tumor specimens, miR-221 expression levels were greater than in adjacent normal tissues (median ratio of tumor to normal of 3.68).

miR-221 expression and clinicopathological features in ovarian cancer patients. The clinical pathology findings in
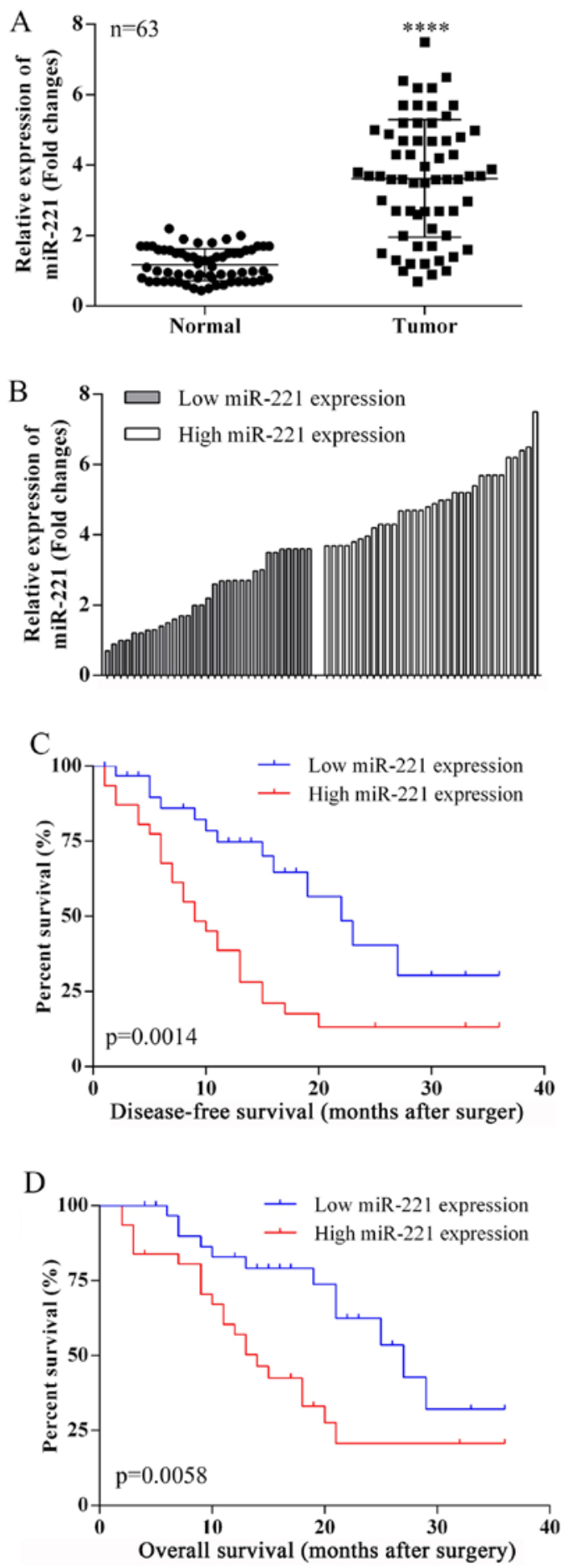

Figure 1. Expression of microRNA-221 (miR-221) in ovarian cancer tissues: clinicopathological correlations. (A) The expression levels of microRNA-221 (miR-221) in ovarian cancer tissues compared with non-tumor tissues $(n=63)$ were detected using quantitative reverse-transcription polymerase chain reaction (qRT-PCR). miR-221 was significantly upregulated in tumor tissues. ${ }^{* * * * *} \mathrm{P}<0.0001$. (B) According to the median ratio of miR-221 expression level (3.68) in tumor tissues, miR-221 expression was classified into two groups: high miR-221 expression group ( $\mathrm{n}=32)$ and low miR-221 expression group $(\mathrm{n}=31)$. (C and D) Kaplan-Meier disease-free survival (DFS) and overall survival (OS) curves according to miR-221 expression level.

63 ovarian cancer patients studied are shown in Table I. The 63 ovarian cancer patients were classified into two groups based on the median relative miR-221 expression (3.68) in ovarian cancer tissues. Group 1: a low miR-221 expression 

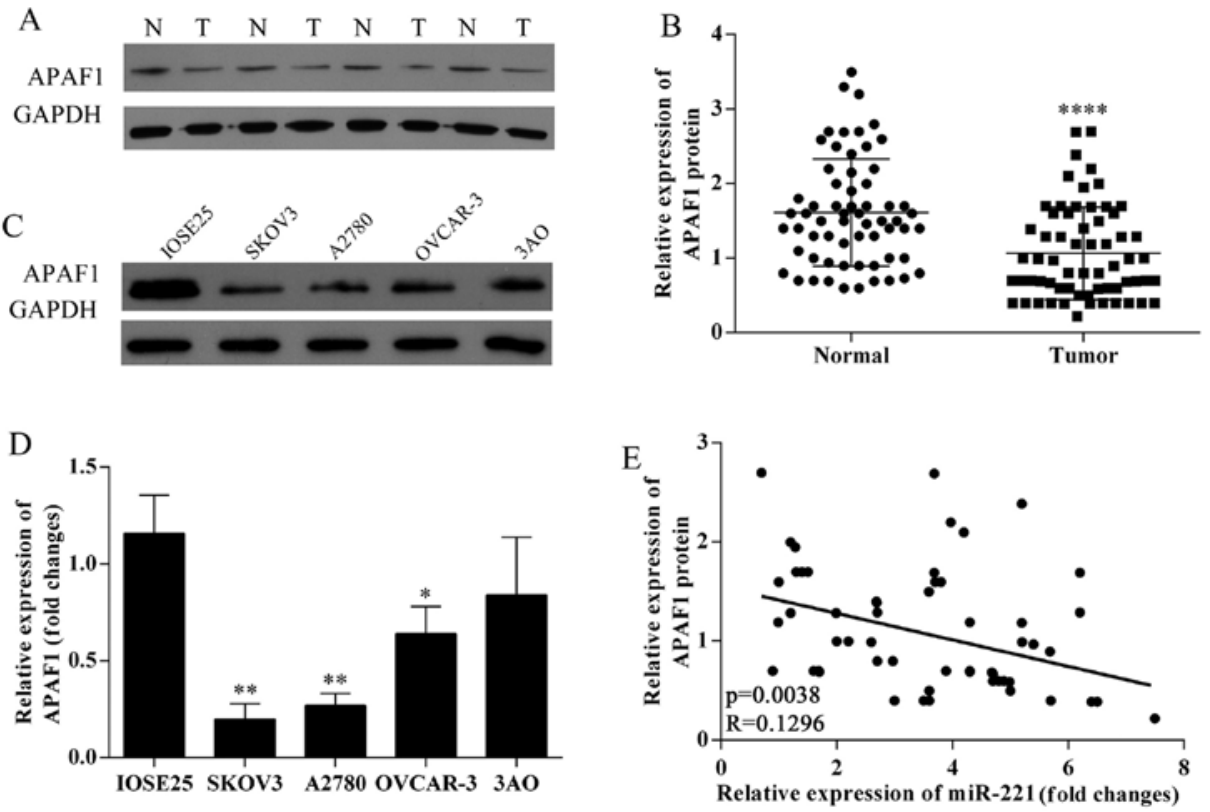

Figure 2. Correlation between microRNA-221 (miR-221) expression level and the apoptosis protease activating factor 1 (APAF1) protein expression in ovarian cancer. (A) Western blot analyzed APAF1 protein expression in ovarian cancer tissues and normal samples. N, normal sample; T, tumor tissues. (B) Quantification of the APAF1 protein bands (O.D. ratio over GAPDH), ${ }^{* * * *} \mathrm{P}<0.0001$. (C) Western blot analysis of APAF1 protein expression in ovarian cancer cell lines. (D) Quantitative reverse-transcription polymerase chain reaction (qRT-PCR) analyzed APAF1 mRNA expression in ovarian cancer cell lines (E) APAF1 protein expression levels were negatively correlated with microRNA-221 (miR-221) expression levels $(\mathrm{P}=0.0038, \mathrm{R}=0.1296)$.
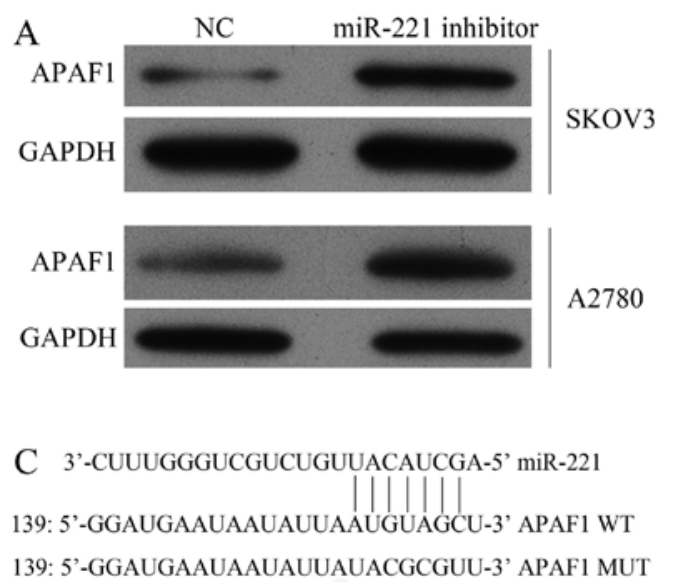
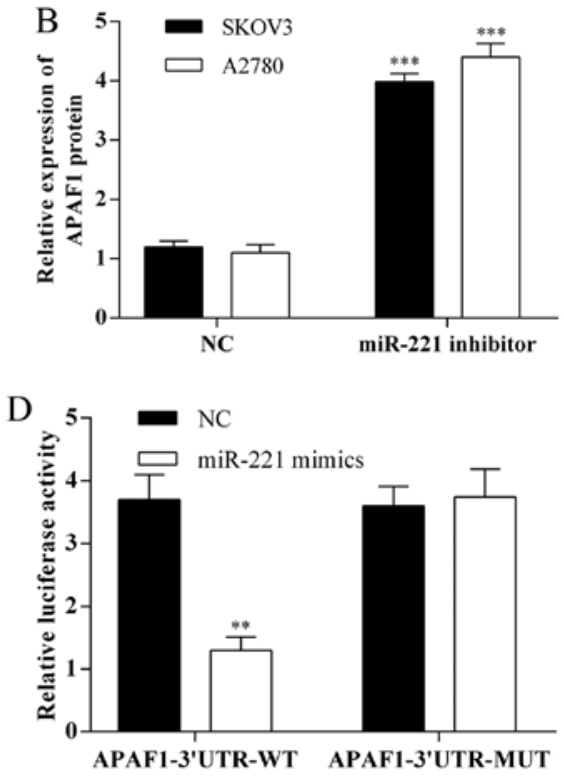

Figure 3. The apoptosis protease activating factor 1 (APAF1) gene is a direct target gene of microRNA-221 (miR-221). (A) The expression of apoptosis protease activating factor 1 (APAF1) protein in SKOV3 and A2780 cells, following miR-221 inhibitor transfection, investigated using western blot analysis. (B) Quantification of the APAF1 protein bands (O.D. ratio over GAPDH). ${ }^{* * *} \mathrm{P}<0.001$. (C) Sequence alignment of miR-221 and 3'-UTR of APAF1 mRNA using TargetScan (www.targetscan.org) and MICRORNA.ORG (www.microrna.org) algorithms. (D) Cells were co-transfected with miR-221 mimics and a luciferase reporter containing a fragment of the APAF1 3'-UTR harboring either the miR-221 binding site (APAF1-3'-UTR-WT) or a mutant (APAF1-3'UTR-MUT). The assay showed that luciferase activity in the APAF1-3'-UTR-WT group was significantly decreased but was increased when compared with the luciferase activity of the mutant groups. ${ }^{* *} \mathrm{P}<0.01$.

group ( $\mathrm{n}=31$, miR-221 expression $\leq$ median). Group 2: a high miR-221 expression group $(n=32$, miR-221 expression $\geq$ median) (Fig. 1B).

A comparison of the clinicopathological features of the two groups is shown in Table II. The high-miR-221 group (group 2) had a larger tumor size $(\mathrm{P}=0.0010)$, deeper depth of tumor invasion $(\mathrm{P}=0.0003)$ and higher FIGO stage $(\mathrm{P}=0.0076)$ when compared with the low-miR-221 group (group 1). However, the miR-221 expression level was not associated with other parameters such as age $(\mathrm{P}=0.8052)$, histologic differentiation (tumor grade) $(\mathrm{P}=0.9463)$, lymphatic spread $(\mathrm{P}=0.4985)$, or distant metastasis $(\mathrm{P}=0.6723)$ (Table II). 

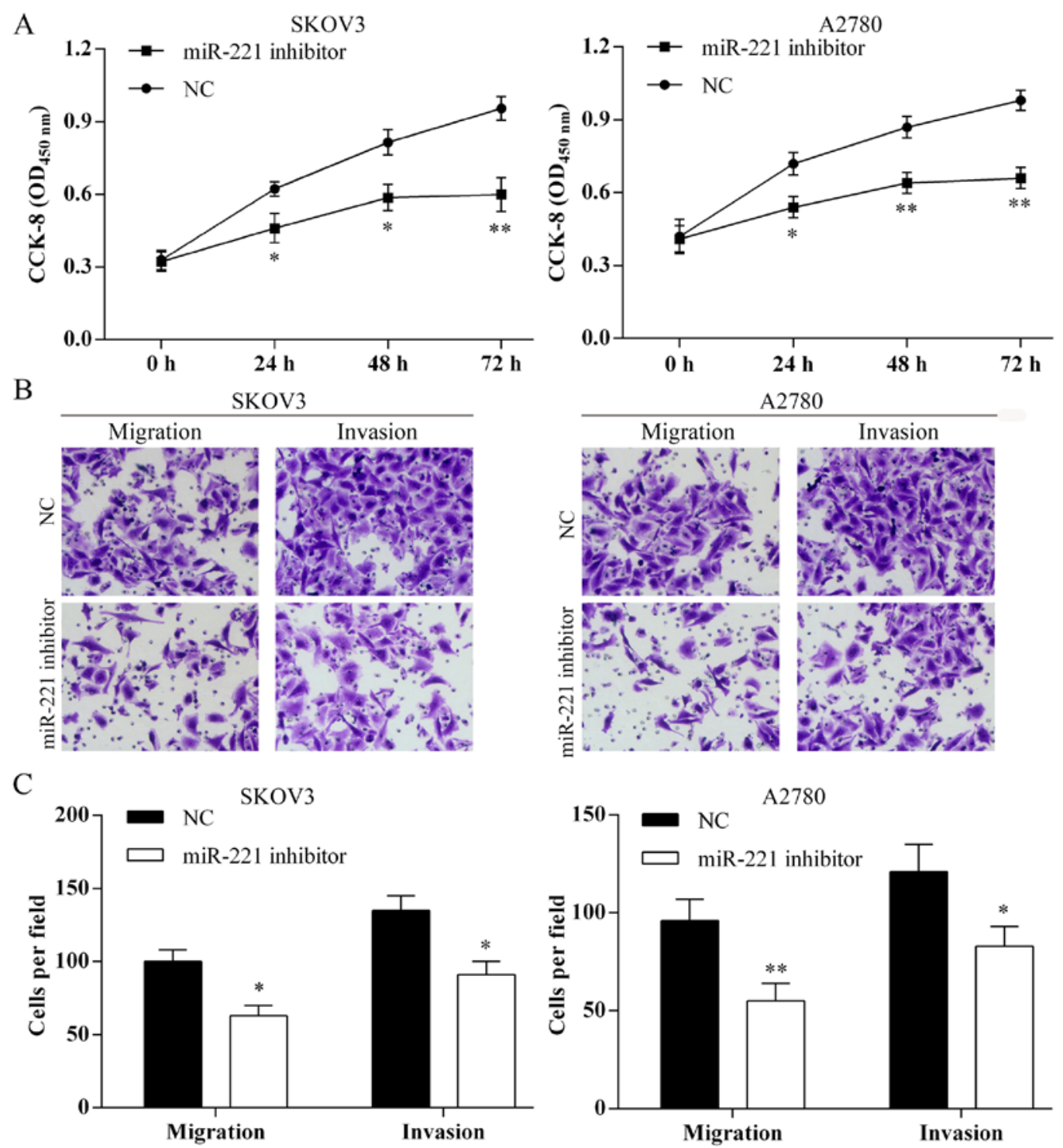

Figure 4. Transfection of microRNA-221 (miR-221) inhibitor suppressed ovarian cancer cell proliferation, migration and invasion. (A) Cell Counting kit-8 (CCK-8) assay results showed that the ovarian cancer cell proliferation was inhibited by miR-221 inhibitor transfection. ${ }^{*} \mathrm{P}<0.05$; ${ }^{* * *} \mathrm{P}<0.01$. (B) Cell migration and invasion were detected using Transwell assay (magnifications, $\mathrm{x} 40$ ). Images of migration and invasion of each cell group are presented. (C) The average migration and invasion cell number per field among different experimental groups. Three independent experiments were performed. ${ }^{*} \mathrm{P}<0.05$; ${ }^{* *} \mathrm{P}<0.01$.

Table III. Primer sequences used for miRNA and mRNA expression analysis.

miR-221-RT

U6-RT

U6-F

U6-R

miR-221-F

Universal-R

APAF1-F

APAF1-R

GAPDH-F

GAPDH-R

\author{
CTCAACTGGTGTCGTGGAGTCGGCAATTCAGTTGAGTGGGGTATT \\ CGCTTCACGAATTTGCGTGTCAT \\ CTCGCTTCGGCAGCACA \\ AACGCTTCACGAATTTGCGT \\ ACACTCCAGCTGGGTGTCAGTTTGTCAA \\ CTCAACTGGTGTCGTGGA \\ TTGCTGCCCTTCTCCATGAT \\ TCCCAACTGAAACCCAATGC \\ TGTTCGTCATGGGTGTGAA \\ ATGGCATGGACTGTGGTCAT
}

F, forward primer; R, reverse primer; RT, reverse transcription primer. 
A

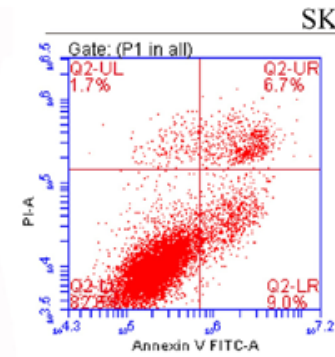

B

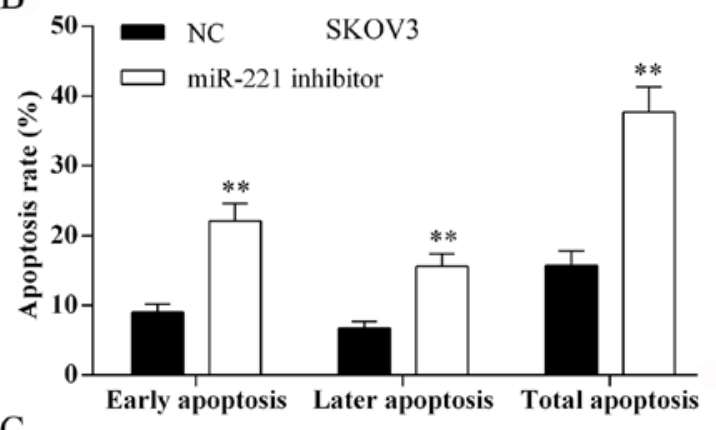

C

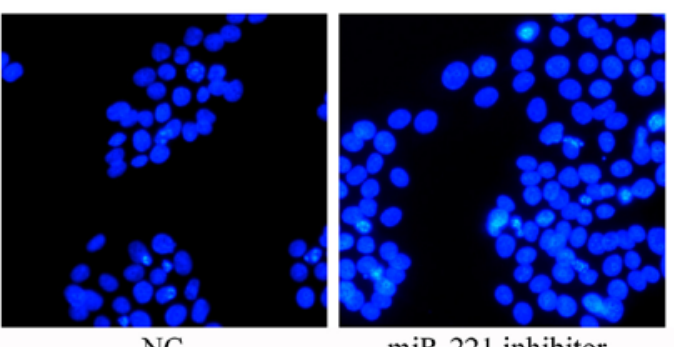

SKOV3

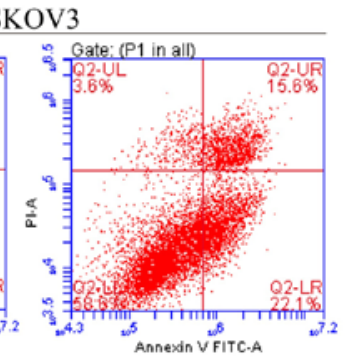

miR-221 inhibitor

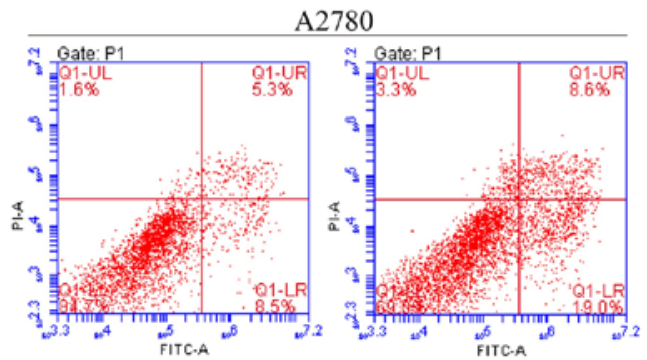

miR-221 inhibitor
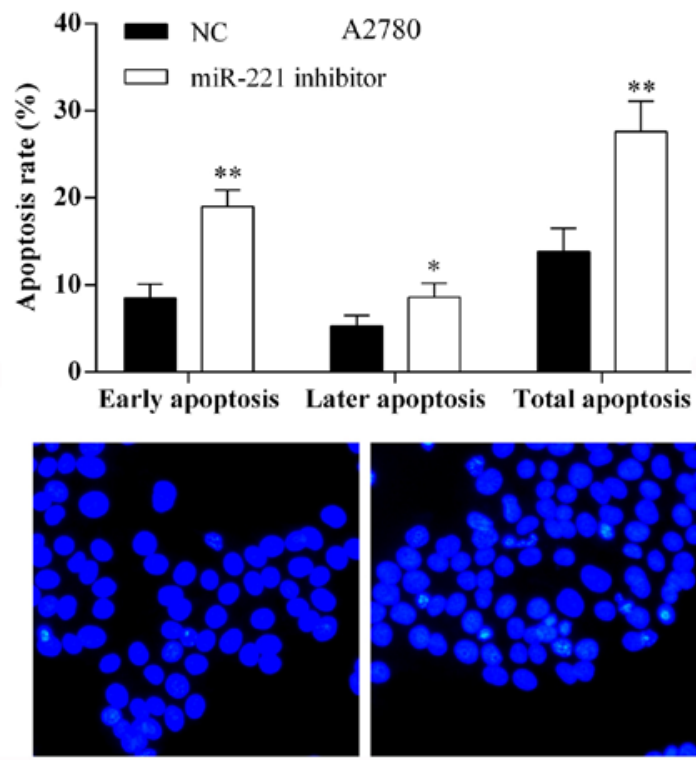

$\mathrm{NC}$

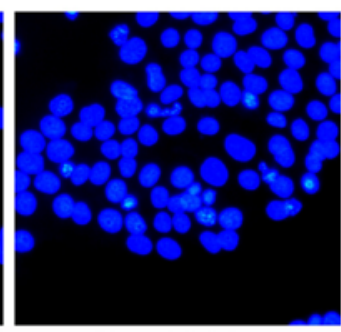

miR-221 inhibitor

A2780

Figure 5. Transfection of microRNA-221 (miR-221) promotes cell apoptosis. (A) Flow cytometric analysis of ovarian cancer cell apoptosis rate following miR-221 inhibitor transfection. LL, viable cells; LR, early apoptotic cells; UR, late apoptotic cells; UL, necrotic cells. (B) The percentage of early apoptotic cells, late apoptotic cells, and total apoptotic cells of each group. ${ }^{*} \mathrm{P}<0.05 ;{ }^{* *} \mathrm{P}<0.01$. (C) Hoechst nuclear staining (blue) assay for SKOV3 and A2780 cells with miR-221 inhibitor transfection cell apoptosis.

miR-221 expression and patient survival. Disease-free survival (DFS) and overall survival (OS) curves were plotted according to miR-221 expression levels, using the Kaplan-Meier analysis and the log-rank test, respectively. The results are presented in Fig. 1C and 1D. Patients with high miR-221 expression levels had a reduced DFS $(\mathrm{P}=0.0014)$ and $\mathrm{OS}(\mathrm{P}=0.0058)$. For the OS, 3 years of overall accumulative survival rates of ovarian cancer patients with low and high miR-221 expression level were 38.57 and $20.68 \%$, respectively. High expression of miR-221 was associated with a greater OS time for ovarian cancer patients (median OS, 14 months) compared with patients with low miR-221 expression (median OS, 27 months). The 3 -year disease-free survival rates for high and low expression of miR-221 patients were 35.21 and $18.54 \%$, respectively. The median survival time for patients with low miR-221 expression was 22 months, and 9 months for patients with high miR-221 expression.

Decreased APAF1 protein expression in ovarian cancer tissues; negative correlation with miR-221 expression. The results of western blotting in ovarian cancer tissues and ovarian cancer lines SKOV3, OVCAR-3, A2780, 3AO and human ovarian surface epithelium cells showed that APAF1 protein expression was downregulated in ovarian cancer tissues (Fig. 2A and B). APAF1 protein expression was downregulated in ovarian cancer cell lines (Fig. 2C). The expression of APAF1 in SKOV3, OVCAR-3, A2780, 3AO and human ovarian surface epithelium cells were detected using qRT-PCR (Fig. 2D); SKOV3 and A2780 cells were chosen for further study. APAF1 protein expression levels were negatively associated with miR-221 expression levels in 63 ovarian cancer tissues ( $\mathrm{P}=0.0038$; $\mathrm{R}=0.1296$; Fig. 2E).

APAF1 as a potential target of miR-221. The expression of APAF1 in SKOV3 and A2780 cells following transfection with miR-221 inhibitor were detected using western blot analysis (Fig. 3A and B). Also, miRNA target predication databases (TargetScan: www.targetscan.org and MICRORNA.ORG: www.microrna.org) were used for computational analysis. miR-221 had one predictive target site in the human APAF1-3'-UTR (Fig. 3C). A Dualluciferase reporter system was used to determine whether APAF1 was a direct target of miR-221. The results showed that miR-221 mimics downregulated the luciferase activity of the reporter and the luciferase expression of mutant APAF1-3'-UTR was not regulated by miR-221 (Fig. 3D). These results indicated that this site of APAF1-3'-UTR was the regulation site for miR-221. 
A
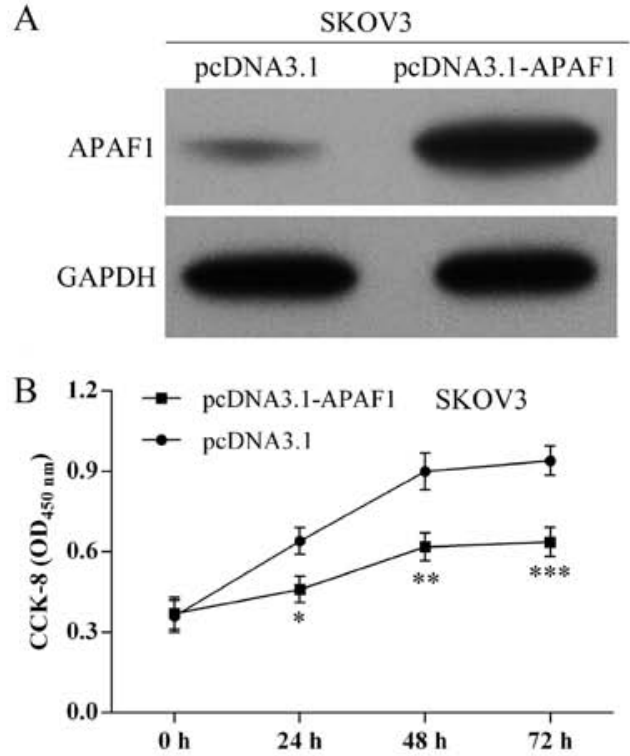

$\mathrm{C}$

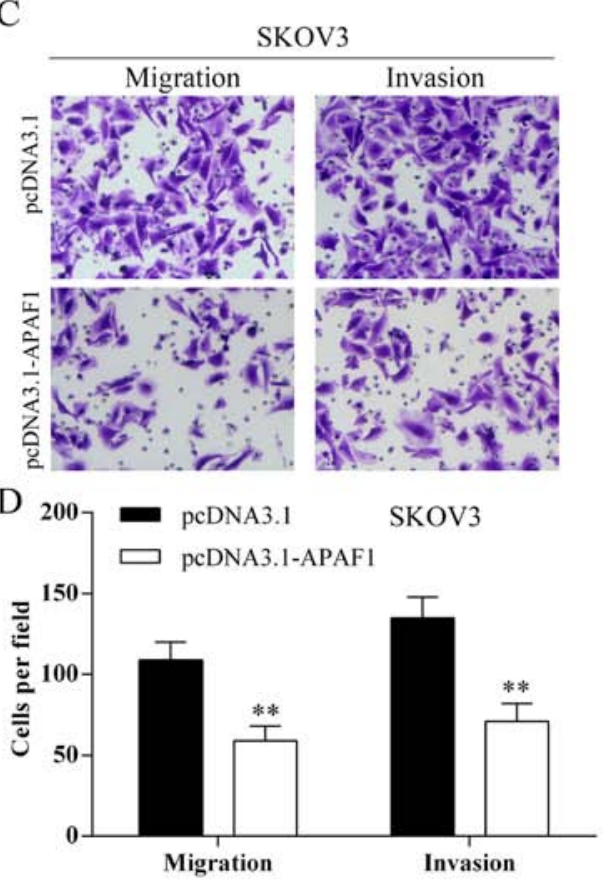

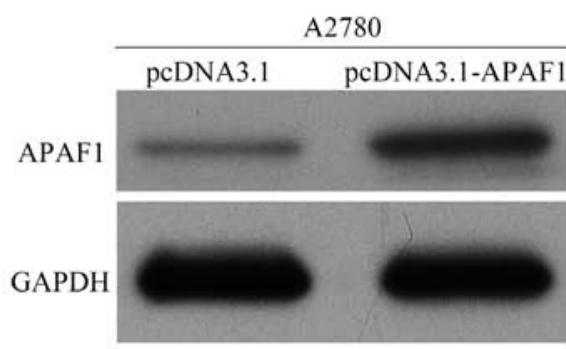
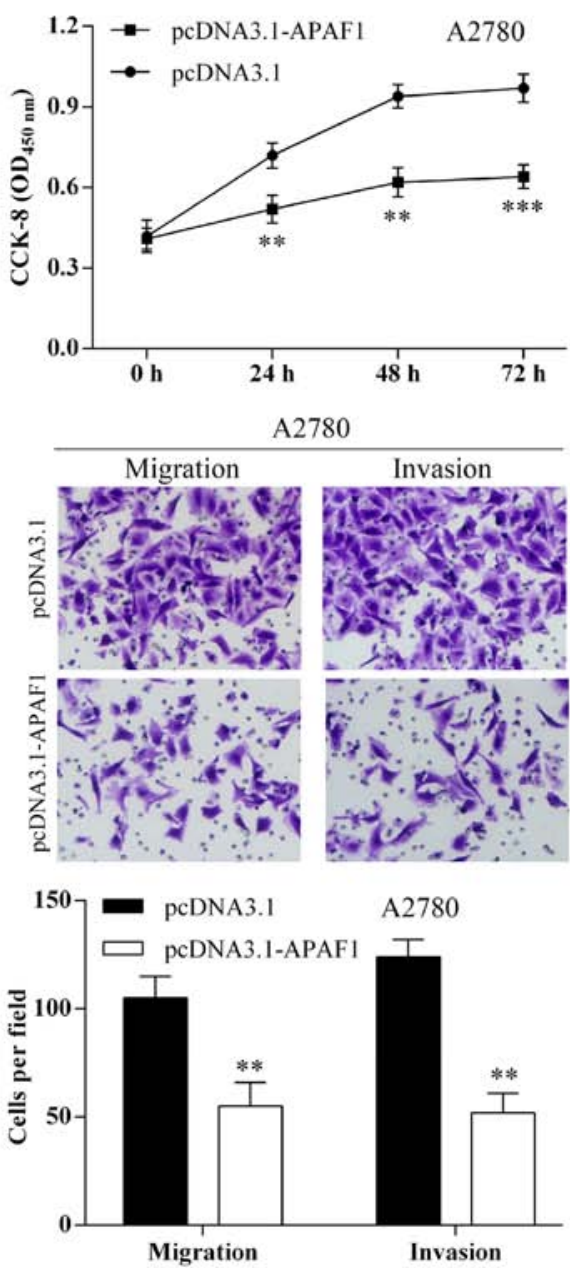

Figure 6. Overexpression of the apoptosis protease activating factor 1 (APAF1) suppresses ovarian cancer cell proliferation, migration and invasion. (A) Western blot analysis was used to detect APAF1 protein expression in ovarian cancer cells after pcDNA301-APAF1 transfection. (B) Cell Counting kit-8 (CCK-8) assay results showed that overexpression of APAF1 inhibited ovarian cancer cell proliferation. ${ }^{* * *} \mathrm{P}<0.001$. (C) Cell migration and invasion were detected using Transwell assay (magnifications, $x 40$ ). Images of migration and invasion of each cell group are presented. (D) The average migration and invasion cell number per field among different experimental groups. Three independent experiments were performed, ${ }^{*} \mathrm{P}<0.05 ;{ }^{* * *} \mathrm{P}<0.01$.

Transfection with miR-221 inhibitor and suppression of ovarian cancer cell proliferation, migration and invasion in vitro. The proliferation of SKOV3 and A2780 cells were suppressed following miR-221 inhibitor transfection (Fig. 4A). Using the Transwell assay the cell migration and invasion of SKOV3 and A2780 were inhibited following miR-221 inhibitor transfection (Fig. 4B and C).

Transfection with miR-221 inhibitor and ovarian cancer cell apoptosis in vitro. Using the Annexin V-FITC/PI staining and Hoechst staining methods, the SKOV3 and A2780 cell apoptosis rates were induced after miR-221 inhibitor transfection (Fig. 5).
Overexpression of APAF1 and suppression of ovarian cancer cell proliferation, migration and invasion in vitro. As shown in Fig. 6A, APAF1 was overexpressed in SKOV3 and A2780 cells following pcDNA3.1-APAF1 transfection. Using the CCK-8 assay, overexpression of APAF1 inhibited ovarian cancer cell proliferation (Fig. 6B). Using Transwell assay, overexpression of APAF1 suppressed the SKOV3 and A2780 cell migration and invasion (Fig. 6C and D).

Overexpression of APAF1 and ovarian cancer cell apoptosis in vitro. The Annexin V-FITC/PI staining and Hoechst staining methods showed that the ovarian cancer cell apoptosis rates were induced following overexpression of APAF1 (Fig. 7). 
A

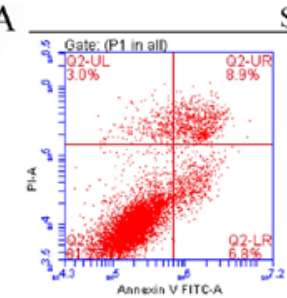

pcDNA3.1
SKOV3

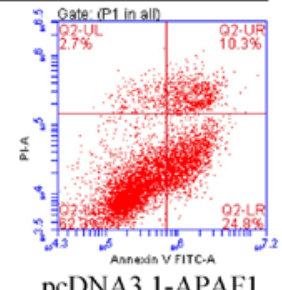

pcDNA3.1-APAF1

B

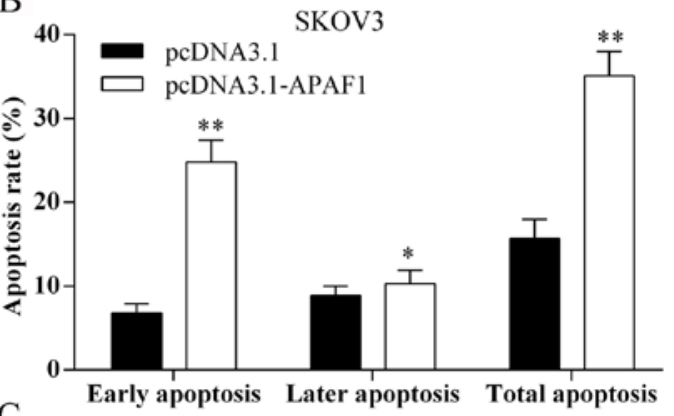

C

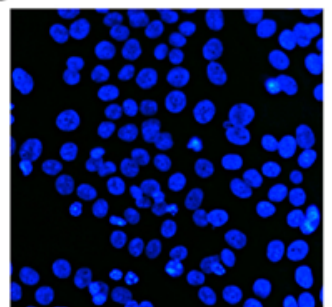

pcDNA3.1

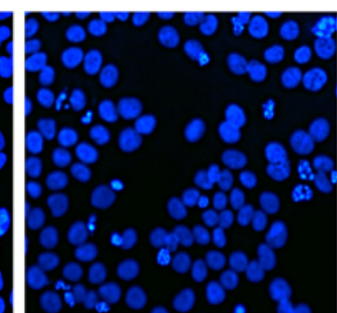

pcDNA3.1-APAF1

SKOV3

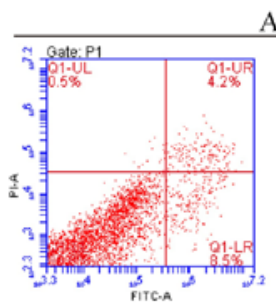

pcDNA3.1
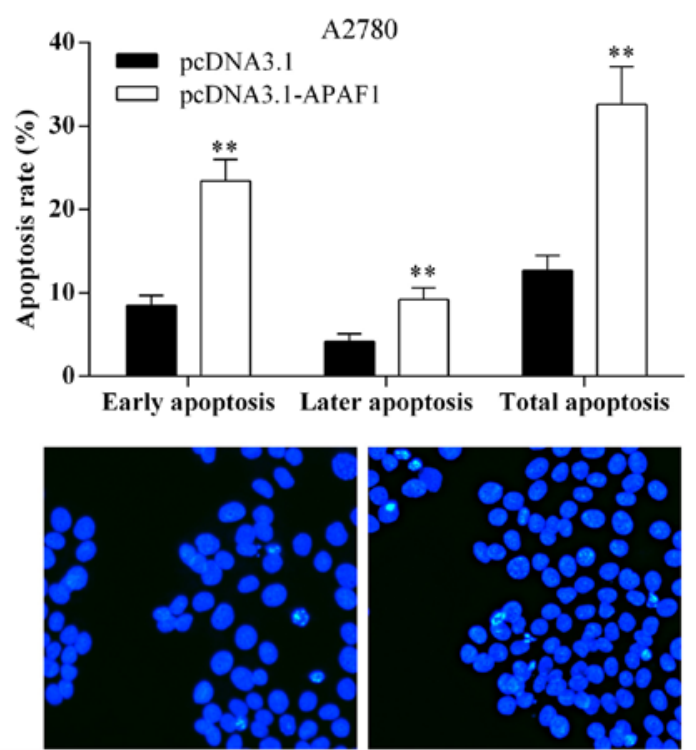

pcDNA3.1

2780

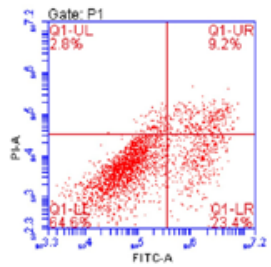

pcDNA3.1-APAF1

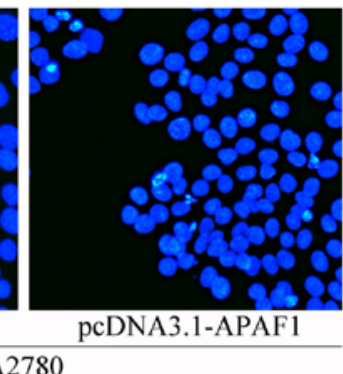

Figure 7. Overexpression of the apoptosis protease activating factor 1 (APAF1) induced ovarian cancer cell apoptosis. (A) Flow cytometric analysis of ovarian cancer cell apoptosis rate after APAF1 overexpression. LL, viable cells; LR, early apoptotic cells; UR, late apoptotic cells; UL, necrotic cells. (B) The percentage of early apoptotic cells, late apoptotic cells, and total apoptotic cells of each group. ${ }^{*} \mathrm{P}<0.05 ;{ }^{* * *} \mathrm{P}<0.01$. (C) Hoechst nuclear staining assay for SKOV3 and A2780 cells with pCDNA3.1-APAF-1 transfection cell apoptosis.

\section{Discussion}

The present study was designed to investigate the expression of microRNA-221 (miR-221) in ovarian cancer tissues and ovarian carcinoma cell lines and to undertake a preliminary study of the prognostic significance of miR-221 in patients following surgery for ovarian carcinoma. The results showed that the expression of miR-221 was increased in ovarian cancer tissues compared with matched adjacent normal tissue. Increased expression levels of miR-221 were associated with increased ovarian tumor size, increased depth of tumor invasion, a higher tumor stage, reduced patient prognosis and survival. Tumor cell transfection with the miR-221 inhibitor induced apoptosis protease activating factor 1 (APAF1) protein expression and confirmed that APAF1 is a target gene for miR-221. Following miR-221 inhibitor transfection, ovarian cancer cell proliferation, migration and invasion were inhibited in vitro and cell apoptosis was induced in vitro. The findings of the present study indicate that miR-221 may act as an oncogene by regulating tumor cell growth, invasion, migration and apoptosis in ovarian cancer, and that miR-221-APAF1 may represent a new potential diagnosis and therapeutic biomarker in ovarian cancer.

The findings of this study on ovarian cancer cell lines and tissue support the finding of other studies on the role of
miR-221 in other types of human cancer $(11,12)$. Also, this study confirmed the findings of other studies on human malignancy that APAF1 expression is associated with inhibition of tumor cell apoptosis $(27,31)$. This study also confirmed that the expression of APAF1 is associated with adverse patient prognosis $(32,33)$. However, this study showed, for the first time that the APAFl gene is a direct target of miR-221 in human ovarian cancer cells and that the overexpression of APAF1 suppressed ovarian cancer cell proliferation and induced cell apoptosis in vitro.

The present study was preliminary in nature, and so further, larger studies are required to confirm and expand the findings. Although multiple tumor cell lines were studied, the behavior of immortalized tumor cells in vitro cannot replicate that of human cancer cells in vitro. For this reason, human ovarian cancer tissues were studied in parallel. However, the number of human tumor samples was small and confined to those from a single center, we suggest that, for future studies, a larger number of tumor samples should be studied and from multiple centers.

In conclusion, the $A P A F 1$ gene was confirmed as a direct target of miR-221 and overexpression of APAF1 suppressed ovarian cancer cell proliferation and induced cell apoptosis in vitro. These findings indicate that miR-221-APAF1 should be studied further as a potential new diagnostic or prognostic biomarker for ovarian cancer. 


\section{Acknowledgements}

We thank Guangzhou Vipotion Biotechnology Co., Ltd. for the assistance in the vector construction of luciferase reporter assay.

\section{References}

1. Torre LA, Bray F, Siegel RL, Ferlay J, Lortet-Tieulent J and Jemal A: Global cancer statistics, 2012. CA Cancer J Clin 65: 87-108, 2015.

2. Breuer EK and Murph MM: The role of proteomics in the diagnosis and treatment of women's cancers: current trends in technology and future opportunities. Int J Proteomics 2011: 373584, 2011.

3. Doench JG and Sharp PA: Specificity of microRNA target selection in translational repression. Genes Dev 18: 504-511, 2004

4. Bartel DP: MicroRNAs: Genomics, biogenesis, mechanism, and function. Cell 116: 281-297, 2004.

5. Filipowicz W, Bhattacharyya SN and Sonenberg N: Mechanisms of post-transcriptional regulation by microRNAs: Are the answers in sight? Nat Rev Genet 9: 102-114, 2008.

6. Meyer SU, Thirion C, Polesskaya A, Bauersachs S, Kaiser S, Krause $S$ and Pfaffl MW: TNF- $\alpha$ and IGF1 modify the microRNA signature in skeletal muscle cell differentiation. Cell Commun Signal 13: 4, 2015.

7. Tian L, Fang YX, Xue JL and Chen JZ: Four microRNAs promote prostate cell proliferation with regulation of PTEN and its downstream signals in vitro. PLoS One 8: e75885, 2013.

8. Ambros V: MicroRNA pathways in flies and worms: Growth, death, fat, stress, and timing. Cell 113: 673-676, 2003.

9. Calin GA, Sevignani C, Dumitru CD, Hyslop T, Noch E, Yendamuri S, Shimizu M, Rattan S, Bullrich F, Negrini M, et al: Human microRNA genes are frequently located at fragile sites and genomic regions involved in cancers. Proc Natl Acad Sci USA 101: 2999-3004, 2004.

10. Hummel R, Hussey DJ and Haier J: MicroRNAs: Predictors and modifiers of chemo- and radiotherapy in different tumour types. Eur J Cancer 46: 298-311, 2010.

11. Nassirpour R, Mehta PP, Baxi SM and Yin MJ: miR-221 promotes tumorigenesis in human triple negative breast cancer cells. PLoS One 8: e62170, 2013.

12. Stinson S, Lackner MR, Adai AT, Yu N, Kim HJ, O'Brien C, Spoerke J, Jhunjhunwala S, Boyd Z, Januario T, et al: TRPS1 targeting by miR-221/222 promotes the epithelial-to-mesenchymal transition in breast cancer. Sci Signal 4: ra41, 2011.

13. Rong M, Chen G and Dang Y: Increased miR-221 expression in hepatocellular carcinoma tissues and its role in enhancing cell growth and inhibiting apoptosis in vitro. BMC Cancer 13: 21,2013.

14. Yamashita R, Sato M, Kakumu T, Hase T, Yogo N, Maruyama E, Sekido Y, Kondo M and Hasegawa Y: Growth inhibitory effects of miR-221 and miR-222 in non-small cell lung cancer cells. Cancer Med 4: 551-564, 2015.

15. Adams BD, Kasinski AL and Slack FJ: Aberrant regulation and function of microRNAs in cancer. Curr Biol 24: R762-R776, 2014.

16. Berindan-Neagoe I, Monroig PC, Pasculli B and Calin GA: MicroRNAome genome: A treasure for cancer diagnosis and therapy. CA Cancer J Clin 64: 311-336, 2014.

17. Hauser B, Zhao Y, Pang X, Ling Z, Myers E, Wang P, Califano J and $\mathrm{Gu}$ X: Functions of MiRNA-128 on the regulation of head and neck squamous cell carcinoma growth and apoptosis. PLoS One 10: e0116321, 2015.
18. Iorio MV and Croce CM: MicroRNA dysregulation in cancer: Diagnostics, monitoring and therapeutics. A comprehensive review. EMBO Mol Med 4: 143-159, 2012.

19. Visone R, Russo L, Pallante P, De Martino I, Ferraro A, Leone V, Borbone E, Petrocca F, Alder H, Croce CM, et al: MicroRNAs (miR)-221 and miR-222, both overexpressed in human thyroid papillary carcinomas, regulate $\mathrm{p} 27^{\mathrm{Kipl}}$ protein levels and cell cycle. Endocr Relat Cancer 14: 791-798, 2007.

20. Fornari F, Gramantieri L, Ferracin M, Veronese A, Sabbioni S, Calin GA, Grazi GL, Giovannini C, Croce CM, Bolondi L, et al: MiR-221 controls CDKN1C/p57 and CDKN1B/p27 expression in human hepatocellular carcinoma. Oncogene 27: 5651-5661, 2008.

21. Medina R, Zaidi SK, Liu CG, Stein JL, van Wijnen AJ, Croce CM and Stein GS: MicroRNAs 221 and 222 bypass quiescence and compromise cell survival. Cancer Res 68: 2773-2780, 2008.

22. O'Hara AJ, Wang L, Dezube BJ, Harrington WJ Jr, Damania B and Dittmer DPP: Tumor suppressor microRNAs are underrepresented in primary effusion lymphoma and Kaposi sarcoma. Blood 113: 5938-5941, 2009.

23. Okamoto K, Miyoshi K and Murawaki Y: miR-29b, miR-205 and miR-221 enhance chemosensitivity to gemcitabine in $\mathrm{HuH} 28$ human cholangiocarcinoma cells. PLoS One 8: e77623, 2013.

24. Cecconi F, Alvarez-Bolado G, Meyer BI, Roth KA and Gruss P: Apaf1 (CED-4 homolog) regulates programmed cell death in mammalian development. Cell 94: 727-737, 1998.

25. Zou H, Henzel WJ, Liu X, Lutschg A and Wang X: Apaf-1, a human protein homologous to $C$. elegans $\mathrm{CED}-4$, participates in cytochrome c-dependent activation of caspase-3. Cell 90: 405-413, 1997.

26. Gao Y, Liang W, Hu X, Zhang W, Stetler RA, Vosler P, Cao G and Chen J: Neuroprotection against hypoxic-ischemic brain injury by inhibiting the apoptotic protease activating factor-1 pathway. Stroke 41: 166-172, 2010.

27. Yong FL, Wang CW, Roslani AC and Law CW: The involvement of miR-23a/APAF1 regulation axis in colorectal cancer. Int J Mol Sci 15: 11713-11729, 2014.

28. De Zio D, Bordi M, Tino E, Lanzuolo C, Ferraro E, Mora E, Ciccosanti F, Fimia GM, Orlando V and Cecconi F: The DNA repair complex Ku70/86 modulates Apaf1 expression upon DNA damage. Cell Death Differ 18: 516-527, 2011.

29. Ho CK, Bush JA and Li G: Tissue-specific regulation of Apaf-1 expression by p53. Oncol Rep 10: 1139-1143, 2003.

30. Marsden VS, O'Connor L, O'Reilly LA, Silke J, Metcalf D, Ekert PG, Huang DC, Cecconi F, Kuida K, Tomaselli KJ, et al: Apoptosis initiated by Bcl-2-regulated caspase activation independently of the cytochrome c/Apaf-1/caspase-9 apoptosome. Nature 419: 634-637, 2002.

31. Mustika R, Budiyanto A, Nishigori C, Ichihashi M and Ueda M: Decreased expression of Apaf-1 with progression of melanoma. Pigment Cell Res 18: 59-62, 2005.

32. Paik SS, Jang KS, Song YS, Jang SH, Min KW, Han HX, Na W, Lee KH, Choi D and Jang SJ: Reduced expression of Apaf-1 in colorectal adenocarcinoma correlates with tumor progression and aggressive phenotype. Ann Surg Oncol 14: 3453-3459, 2007.

33. Zlobec I, Minoo P, Baker K, Haegert D, Khetani K, Tornillo L, Terracciano L, Jass JR and Lugli A: Loss of APAF-1 expression is associated with tumour progression and adverse prognosis in colorectal cancer. Eur J Cancer 43: 1101-1107, 2007.

34. Li NF, Broad S, Lu YJ, Yang JS, Watson R, Hagemann T, Wilbanks G, Jacobs I, Balkwill F, Dafou D, et al: Human ovarian surface epithelial cells immortalized with hTERT maintain functional pRb and p53 expression. Cell Prolif 40: 780-794, 2007. 